\title{
La ambición y carrera política en el nivel subnacional peruano ${ }^{+}$
}

\author{
JOSÉ INCIO* \\ University of Pittsburgh \\ j.incio@pitt.edu \\ CARMEN CHAVARRÍA** \\ Universidad Nacional Mayor de San Marcos \\ beatriz.chrz@gmail.com \\ https://doi.org/10.18800/rcpg.201602.004
}

\section{RESUMEN}

Los políticos, su comportamiento y dinámicas cobran especial relevancia en contexto donde los partidos políticos son débiles y el sistema político presenta poca institucionalización. En este artículo tratamos de conocer los distintos tipos de carrera política de los políticos locales en Perú. Con este objetivo hemos sistematizado y organizado información — provista por el portal Infogob del Jurado Nacional de Elecciones (JNE) — de más de 22 mil políticos locales, quienes iniciaron su carrera política como alcaldes o regidores distritales en tres momentos distintos: 1980, 1993 y 2002. Estos tres hitos representan quiebres importantes en la historia política peruana, por lo que hipotetizamos que generan distintos incentivos, que nos ayuda a explicar la ambición del político local y los diferentes caminos que toma su carrera. Evidenciamos que los cambios institucionales producto de las reformas del proceso de descentralización generan mayores incentivos para que el político local tenga una carrera política progresiva.

Palabras clave: ambición política, generación, alcalde, regidor, carrera política.

\section{The ambition and political career at the Peruvian subnational level}

\begin{abstract}
Politicians, their behavior and dynamics are especially relevant in context where political parties are weak and the political system has little institutionalization. In this article we try to know the different types of political career of local politicians in Peru. To this end, we have systematized and organized information-provided by the Infogob portal of the National Elections Board (JNE) — of more than 22,000 local politicians, who began their political career as mayors or district councilors at three different times: 1980, 1993 and 2002. These three milestones represent important breakthroughs in Peruvian political history, so we hypothesize that they

\footnotetext{
* Estudiante en el Doctorado de la Universidad de Pittsburgh e investigador del Grupo sobre Política Subnacional de la PUCP.

** Licenciada en Ciencia Política por la Universidad Nacional Mayor de San Marcos.
}

+ Recibido el 8 de enero de 2017; aceptado 19 de marzo de 2017.
\end{abstract}


generate different incentives, which helps us explain the ambition of the local politician and the different paths that his career takes. We show that the institutional changes resulting from the reforms of the decentralization process generate greater incentives for the local politician to have a progressive political career.

Key words: political ambition, generation, mayor, regidor, political career. 


\section{INTRODUCCIÓN}

En estos tiempos de creciente desafección y desapego de la ciudadanía con los políticos, es común generalizar y asumir que todos ellos son corruptos o tienen ansias inacabables de poder y dinero, pero ¿es así? ¿Cuánto conocemos del político peruano? En este artículo estamos enfocándonos en la ambición del político electo a nivel local y el tipo de carrera política que lo caracteriza. En ese sentido, buscamos aportar en dos dimensiones. Primero, describiendo de manera sistemática, dialogando con la literatura y teoría que aporta la ciencia política, los tipos de carrera política del político local. Segundo, poniendo a disposición de la academia una base de datos organizada y sistematizada sobre este tema, que permita plantearse nuevas hipótesis de trabajo.

Si bien este es un trabajo descriptivo, hemos optado por analizar la ambición política subnacional haciendo tres cortes generacionales de los alcaldes y regidores según su primera elección: 1980, 1993 y 2002. Esta distinción entre una y otra generación intenta representar tres momentos importantes del sistema político peruano, cada uno con formas particulares de hacer política. Nuestra hipótesis es que los contextos de cada generación, en cierta forma, determinan el tipo de ambición y por ende la carrera del político local. Debemos precisar que con esta investigación no buscamos determinar las causas de la ambición de los políticos locales, ni inferir las razones que expliquen la selección de los cargos a los cuales postulan los políticos, sino explorar en las diferencias de cada una de las tres generaciones en cuanto a ambición y carrera política.

Los procesos municipales de 1980 se desarrollaron en un contexto de transición hacia un régimen democrático, por lo que las expectativas para el desarrollo de una carrera política de largo aliento podrían ser justificadamente altas. Además, los partidos políticos contaban aún con cierta reputación y presencia a nivel nacional, y se vivía en el país un sistema político con partidos políticos estables y claramente representativos del espectro ideológico izquierdaderecha. En contraste, los procesos municipales de 1993 se llevan a cabo en un contexto post crisis institucional, donde los partidos han perdido presencia y el Perú se encontraba en una profunda crisis económica y social. La antipolítica se torna la norma y los independientes llenan el espacio dejado por los partidos. Por lo tanto, esperamos que en este contexto el político local sea más adverso al riesgo y no tenga incentivos para arriesgar su feudo o posición. Finalmente, los comicios municipales de 2002 se desarrollaron en el marco

La base de datos estará disponible en www.joseincio.com/data. 
del proceso de descentralización. Este escenario construyó un nuevo campo para la competencia política, ya que se creó un nuevo nivel de gobierno: los gobiernos regionales. Esperamos que este nuevo arreglo institucional brinde mayores expectativas al político local, generando un incremento en su movilidad en posiciones políticas y asuma mayor riesgo. En resumen, los cortes generacionales responden a contextos que creemos pueden motivar una ambición progresiva, en 1980 y 2002, o una ambición estática, en 1993. Los tipos de ambición, los discutiremos en las siguientes secciones.

En la primera parte del artículo se revisan aspectos teóricos sobre ambición y carrera política. Nuestro principal insumo es la profusa literatura que ha analizado el caso de los legisladores estadounidenses. También tomamos como referencia las carreras legislativas en el caso brasileño y argentino. Revisar estos trabajos nos permitiría encontrar elementos que nos ayuden a una mejor descripción de la carrera de los alcaldes y regidores distritales en Perú.

En la segunda parte discutimos el contexto de las elecciones subnacionales peruanas. El proceso de consolidación de la arena subnacional peruana, las diferencias con la arena nacional, así como las oportunidades y limitaciones que tienen los políticos para realizar la transición de uno a otro ámbito de gobierno.

En la tercera parte, se realiza una breve descripción sobre las primeras aproximaciones al estudio de la ambición relacionadas a la reelección. En la siguiente sección se explican cada una de las tres generaciones, el criterio de selección y procesos electorales que abarcan. Luego se presentan los cinco tipos de carreras políticas construidas que se van a aplicar para analizar la ambición de los regidores y alcaldes, así como las trayectorias que comprenden cada una de ellas.

Finalmente, en la última parte del artículo se exponen los resultados del análisis de la ambición y carrera política de los alcaldes y regidores que representan las generaciones de 1980, 1993 y 2002. Además, describimos los tipos de carrera política que las generaciones han emprendido, se conocerán los niveles de gobierno a donde los políticos locales de cada generación han orientado preferentemente su ambición.

\section{AMBICIÓN Y CARRERA POLÍTICA}

La ambición de un político determina las decisiones que toma a lo largo de su carrera política. La ciencia política norteamericana ha dedicado especial atención a entender los tipos de ambición política de los legisladores estadounidenses y cómo esta determina su comportamiento y posteriores decisiones. 
La literatura respecto a patrones de las carreras políticas está inspirada en el Congreso estadounidense. Schlesinger (1966) y Mayhew (1974), sus principales exponentes, sostienen que la carrera política es de naturaleza lineal: el legislador busca reelegirse por el mismo cargo y por varios periodos consecutivos para luego avanzar a un cargo de mayor jerarquía. Para los electores estadounidenses, los políticos electos por periodos consecutivos son vistos como las personas más idóneas y capaces, justamente por la experiencia que logran adquirir tras los años en el cargo. Estos autores destacan la importancia de que el legislador — una vez electo - actúe de forma responsable frente a las demandas de los electores a fin de mantener una base de apoyo fiel, en caso pretenda postular en una siguiente elección.

Los políticos de carrera postulan por periodos consecutivos, en su afán de sumar experiencia a su desempeńo y profundizar sus carreras; por el contrario, los políticos efímeros ocupan su cargo por un periodo y luego desaparecen. Por ello, entienden que la aparición de políticos de carrera promueve nexos más fuertes entre ellos y los ciudadanos, ya que los políticos de carrera tienden a ser más responsables frente a las demandas de los electores, quienes a su vez buscan políticos que promuevan sus intereses (Botero, 2011, p. 171).

Como se ha dicho, el punto de partida para el estudio de la ambición política han sido las decisiones que toman los políticos respecto al futuro de sus carreras. En el caso de los políticos que ya ocupan un cargo de elección, las decisiones se debaten entre el retiro, la reelección o la búsqueda de otros puestos de elección. Para Schlesinger (1966), un político posee «ambición estática» cuando demuestra interés por mantenerse en carrera desde el mismo cargo $\mathrm{y}$ «ambición progresiva» cuando aspira a un puesto superior al que ocupa en un momento determinado. Mientras que la «ambición discreta» ocurre cuando el político ocupa un cargo por un periodo específico y luego se retira de la actividad pública.

Los objetivos electorales en los incumbentes influencian en el desempeño de sus funciones. De acuerdo con Miller y Stokes (1963), el interés por cargos de elección de mayor jerarquía afecta el comportamiento de los legisladores ya que los impulsa a actuar de una forma más responsable frente a las demandas de los electores a fin de mantener una base de apoyo fiel que les permita tener mayores probabilidades de ganar en caso postulen en una siguiente elección (como se cita en Díaz, 2005, p. 316). Más adelante, Schlesinger sostendría que si bien la ambición repercute en las decisiones sobre el futuro de una carrera política, existen también diversos factores que actúan sobre el escenario político que moldean la ambición. En ese sentido, dependerá también de la habilidad 
de los políticos para saber aprovechar las oportunidades del entorno y tomar las decisiones que le permita llegar a sus objetivos (Schlesinger, 1966, pp. 45-56).

En cuanto a los incumbentes interesados en la reelección, un grupo de estudios señala que el ocupar un cargo les daría a los legisladores una ventaja frente a los aspirantes que no ocupan uno (Erickson, 1971; Ferejohn, 1977; Abramowitz, 1991; Gardner, 1991; Schaffner, Streb y Wright, 2001). Según la teoría de los incumbentes, existen diferentes factores relacionados a la ventaja de los incumbentes que afectan la competencia electoral al introducir «sesgos» a favor de unos participantes y en contra de otros (Botero, 2011, p. 176).

Por un lado, la experiencia de los legisladores representa para los electores estadounidenses uno de los atributos más importantes para elegir a un candidato, ya que les permite cumplir mejor su papel como representantes al tener acceso a mejores cargos y, en general, a más recursos para gestionar los intereses de los electores (Botero, 2011, p. 177). De ahí que el desempeño electoral de un incumbente se proyecte a tener mejores resultados que el de un político nuevo, ya que la reelección le da al legislador la oportunidad de acumular experiencia y capital político. Sin embargo, el incumbente deberá superar el obstáculo de ganar su primer intento de reelección, donde las probabilidades de éxito son menores. Una vez reelecto, cada vez le será más sencillo lograr ser reelegido repetidamente porque para los incumbentes los costos para obtener un cargo y mantenerse en el mismo se reducen. No obstante, para el caso estadounidense, existe un punto de saturación de la reelección, que se da luego del séptimo u octavo periodo consecutivo, «después del cual la experiencia y la duración de la carrera se vuelven una desventaja» (Botero, 2011, p. 177).

Por otro lado, la presencia de partidos dominantes también tiene influencia en la competencia electoral. El político que postula a través de un partido dominante se encuentra en ventaja frente al resto de candidatos en su ambición de construir una carrera, ya que para los segundos sus probabilidades de ganar son menores al enfrentar un escenario adverso, sin mayoría en el Parlamento, donde tendrán que evaluar el futuro de su carrera legislativa y su permanencia en otros cargos de elección.

Para el caso estadounidense, la reelección constituye el medio más frecuente entre los legisladores para lograr una carrera política a largo plazo (Botero, 2011, p. 179). La suma de periodos consecutivos en la carrera de los políticos les permite no solo acumular experiencia al desempeño de sus funciones, sino también la posibilidad de profundizar sus carreras. Para Miller y Stokes (1963), la aparición de políticos de carrera promueve nexos más fuertes entre ellos y los ciudadanos, a diferencia de un político efímero que ocupa un cargo por 
un periodo y luego desaparece. Como mencionamos líneas arriba, los políticos de carrera tienden a ser más responsables frente a las demandas de los electores, quienes a su vez buscan políticos que promuevan sus intereses (como se cita en Botero, 2011, p. 171).

El contexto en el que se desarrolla la ambición política en el legislativo estadounidense difiere en ciertos aspectos con el latinoamericano, donde las carreras no se construyen necesariamente a través de la reelección o en el legislativo (Botero, 2011, pp. 178-180). La competencia por cargos en el legislativo estadounidense tiene un sistema mayoritario con distrito uninominal donde los políticos tienen la opción de establecer una relación más cercana con sus electores. Por otra parte, en los Estados Unidos opera un sistema bipartidista que permite la conformación clara de partidos mayoritarios que potencialmente pueden monopolizar la formulación de políticas públicas para usarlas en su beneficio y aportar positivamente en su reputación (Crisp y Desposato, 2004 en Botero, 2011, p. 179). De igual forma, el balance de poderes entre el ejecutivo y legislativo estadounidense ofrece incentivos a los políticos para desarrollar carreras de largo plazo, al contar el legislativo con niveles altos de institucionalización y permitirle al político mayores opciones de profesionalizarse (Botero 2011, p. 180).

Para el caso latinoamericano, por el contrario, se aplican fórmulas de representación proporcional con distritos plurinominales, donde un mismo distrito electoral puede tener representantes de distintos partidos, lo cual acentúa la competencia partidaria, haciendo menos dominante la presencia de un partido en el distrito (Crisp y Desposato, 2004 en Botero, 2011, p. 179). Respecto al balance de poderes, lo que se observa en el caso latinoamericano es la presencia de congresos no institucionalizados que no ofrecen a los políticos incentivos para desarrollar carreras legislativas, orientando su ambición hacia posiciones ubicadas en los gobiernos regionales o locales. En ese sentido, es de esperarse que esta situación dificulte la transición de la arena nacional a la subnacional.

\subsection{La ambición política: caso argentino y brasileño}

Como se ha dicho antes, los estudios sobre la ambición política se han centrado en las carreras legislativas, principalmente la carrera de los diputados, pero poco se ha profundizado en el tipo de ambición que manifiestan los políticos de los gobiernos municipales (Schlesinger, 1966; Miller y Stokes, 1963; Black 1972; Rohde, 1979; Aldrich y Bianco, 1992). Sin embargo, el cuerpo teórico desarrollado por esta literatura nos permite dilucidar sobre los aspectos adecuados a analizar en el ámbito subnacional peruano. En especial las categorías utilizadas para la clasificación de la ambición y carreras legislativas, que bien pueden ser 
utilizadas como punto de partida para entender mejor la política subnacional peruana.

En América Latina tenemos investigaciones realizadas por Jones (1997, 2001, 2008), Jones, Saiegh, Spiller y Tommasi (2002), Micozzi (2009), Lodola (2009) y Samuels (2011) que se remiten a la teoría de la ambición para estudiar las carreras legislativas en Argentina y Brasil, países federales. Estas investigaciones han evidenciado que las carreras legislativas resultan menos atractivas, mientras que los puestos subnacionales funcionan como un mejor incentivo para los políticos que proyectan construir una carrera.

El caso argentino fue analizado por Jones et al. (2002), para quienes las carreras que emprenden los políticos de dicho país eran similares a los patrones norteamericanos, donde el primer escalón de una carrera política comenzaba por el nivel más bajo de los cargos ejecutivos, mientras que las diputaciones nacionales representaban para los argentinos el «trampolín hacia puestos superiores por un número sustancial de políticos» (como se cita en Campomar y Delneri, 2012, pp. 7-10). Micozzi (2009) retoma el estudio de las carreras políticas y encuentra que empiezan en el nivel municipal, para pasar luego al provincial, en razón del interés cada vez mayor de los políticos por los cargos de gobernadores e intendentes que se disputan en las elecciones subnacionales, considerados puntos centrales para lograr poder partidario. Cabe precisar que Argentina posee un sistema federal donde los gobernadores de las provincias tienen una considerable autoridad en materia de políticas públicas, recursos fiscales y gran poder de discrecionalidad en las decisiones (Campomar y Delneri, 2012, p. 8). En ese sentido, el cargo de gobernador es uno de los puestos más importantes en Argentina, después del presidente y algunos ministerios (Jones, 1997; Almaraz, 2010).

El gobernador no solo controla presupuestos importantes y ejerce influencia sobre áreas vitales como educación, salud y seguridad pública. Los gobernadores como cabezas del poder ejecutivo de las provincias cumplen también un rol estratégico en las elecciones, ya que poseen recursos y redes clientelares muy valorados por los políticos que aspiran alcanzar puestos de poder en la arena subnacional. En ese sentido, la relevancia de la política provincial argentina se explica en la interdependencia que existe entre los actores de la política local y la nacional en el contexto de un proceso electoral, donde los primeros dependen de los gobiernos nacionales en cuanto a recursos electorales, fiscales o de políticas públicas; mientras que los políticos que aspiran a puestos nacionales necesitan crear bases provinciales de apoyo a fin de que las máquinas locales del partido supervisen las campańas, el acto eleccionario y el escrutinio (Almaraz, 2010, p. 194). 
La notoriedad que adquiere el nivel provincial en la dinámica de la competencia electoral argentina ha hecho que muchos políticos busquen alcanzar puestos de la arena subnacional a través de puestos nacionales, tal es el caso de las diputaciones argentinas que normalmente son utilizadas como el medio hacia puestos ejecutivos (Jones, 1997; Lodola, 2009; Almaraz, 2010). Para Lodola, las carreras legislativas argentinas no son prolongadas, ya que los diputados puede que no busquen la reelección, sino postular hacia otros cargos electivos. En lo que refiere a las carreras políticas de los gobernadores argentinos, en un estudio sobre los electos entre los años 2003 y 2011, se encontró que gran parte de los gobernadores iniciaron sus carreras desde ese puesto ejecutivo, sin acumular experiencia en otro cargo público, en tanto el 30\% había ocupado previamente un cargo electivo o por designación (Campomar y Delneri, 2012, p. 27).

En el caso brasileño, investigaciones sobre carreras políticas señalan que llegar al poder legislativo no es el principal objetivo. Para Samuels (2011), el interés de los diputados brasileños por desarrollar carreras legislativas de largo plazo es menor. Por el contrario, los diputados están interesados por cargos fuera de la legislatura. De acuerdo con Samuels, dos tercios de los políticos continuaron con una carrera postlegislativa en el nivel subnacional y por lo menos el $40 \%$ de los diputados en servicio pidieron licencia para participar en el gobierno local o estadual o para presentarse a alcalde municipal (Samuels, 2011, pp. 293-294).

Por otra parte, Samuels señala que los patrones de reclutamiento de los partidos brasileños influyen en el tipo de carrera políticas que desarrollan los candidatos. La debilidad organizacional de los partidos coloca a sus líderes en desventaja al contar con pocos recursos para mantener en línea a candidatos emprendedores, políticos que podrían cambiarse de partido en cuanto vean afectada su ambición. Brasil cuenta con un federalismo fuerte que acentúa el poder local y regional, mientras que el sistema proporcional con lista abierta y un umbral electoral bajo fomentan el individualismo y la fragmentación del sistema de partido al debilitar el poder de los partidos nacionales (Siavelis y Morgenstern en Samuels, 2011, p. 282). Las oportunidades de construir una carrera en la legislatura brasileña se hacen poco factibles, donde más bien se observa una carrera legislativa carente del escalafón para ascender en el mismo y donde la presencia de partidos legislativos fuertes reduce las opciones de los políticos de avanzar en sus ambiciones.

Los casos argentino y brasileño evidencian la importancia del ámbito subnacional como espacio para la carrera de un político. Ahora bien, ambos casos 
son países federados, donde los cargos subnacionales cuentan con considerable autonomía y recursos. Para el caso peruano, no debemos perder de vista que es un país unitario y que el proceso de descentralización empezó recién en 2001. Por lo tanto, el nivel nacional y subnacional contienen diferencias sustanciales que evitan/retienen un mayor traslado de los políticos entre un nivel u otro.

\section{CONTEXTO Y CONSOLIDACIÓN DE LA ARENA SUBNACIONAL: CASO PERUANO}

Las elecciones municipales por votación directa y universal se realizaron por primera vez el 15 de diciembre de 1963, con lo cual se terminaba con un periodo de más de cuarenta años, durante el cual las autoridades locales eran nombradas por el Ministerio de Gobierno ${ }^{2}$. Antes de esa fecha, las elecciones para diputados eran las que concentraban las votaciones a nivel departamental o provincial $^{3}$.

En las elecciones generales de 1963, Fernando Belaunde —en aquel entonces en alianza con el partido Demócrata Cristiano- triunfó con el 36,2\% de la votación; sin embargo, la mayoría en el Congreso recayó en la alianza entre el APRA y la Unión Nacional Odriísta. Las elecciones municipales — realizadas seis meses después - despertaron un gran interés en la ciudadanía, que luego de un largo periodo acudía a votar, y, en especial, en las dos fuerzas partidarias que obtuvieron la mayoría de los escańos en el Legislativo: Acción Popular y el Partido Aprista Peruanó. Para los políticos de Acción Popular, obtener la mayoría de las municipalidades era la oportunidad para cambiar en algo el escenario adverso en el que se encontraban en el Congreso; mientras que para la coalición APRA-UNO, replicar su control a nivel subnacional le permitiría ganar terreno en sus ambiciones. En efecto, los resultados electorales de los comicios municipales de 1963 posicionaron a la Alianza Acción PopularDemócrata Cristiano en el 48,8\% de los distritos, seguido del 41,9\% de la alianza APRA-UNO.

En diciembre de 1963, veintiséis candidatos que habían postulado al Parlamento meses atrás, se presentaron también como candidatos a cargos municipales, de los cuales dieciocho lograron ser electos. Con la convocatoria a elecciones municipales, la competencia electoral se expandió a nuevos terrenos

\footnotetext{
2 En 1968, con el Gobierno militar se regresó a los nombramientos de las autoridades locales desde el ejecutivo.

3 En el proceso de 1936, 1939 y 1945 los distritos electorales se determinaron, en la elección de diputados, sobre la base de las provincias.

4 Acción Popular se presentó nuevamente en alianza con el partido Demócrata Cristiano y el Partido Aprista Peruano, en coalición con la Unión Nacional Odriísta.
} 
y se habilitaron nuevos espacios de representación política. No obstante, por un golpe de Estado, este proceso se vio interrumpido en el año 1968, pero sería retomado en 1980 con las elecciones municipales, tras el fin de la dictadura militar. A partir de ese momento, la arena subnacional pasó a constituirse nuevamente en una oportunidad para los políticos de desarrollar una carrera desde lo local y que cobrará mayor impulso en el año 2002 con la realización por primera vez de las elecciones regionales. Además de retomarse el camino a la descentralización trazado años atrás, la creación de los gobiernos regionales, con un peso político y administrativo considerable, agregó nuevos incentivos en la carrera de los políticos locales, al ofrecer un escalón más5.

En la arena subnacional las opciones políticas para postular a una candidatura son variadas - a diferencia de lo que ocurre en las elecciones generales, donde solo pueden participar partidos y alianzas - ; no obstante, la competencia electoral se centra básicamente entre los partidos políticos y movimientos regionales. Sin embargo, la presencia de los partidos políticos en los ámbitos subnacionales ha entrado en franco retroceso. Como menciona Seifert (2014), los partidos políticos nacionales han perdido espacio en el ámbito subnacional, dejando de presentar candidatos y teniendo una muy baja tasa de éxito en las elecciones provinciales y distritales. Como ejemplo, tomemos las elecciones para la presidencia y vicepresidencia regional de 2014, donde se refleja el predominio de los movimientos regionales, pues ganaron doce de las veinticinco presidencias regionales; mientras que los partidos políticos solo en seis.

\subsection{Transición de la arena subnacional a la nacional}

La división entre esfera nacional y subnacional que planteamos está construida sobre la base de una barrera artificial creada por la Ley de Partidos Políticos, que excluye a los movimientos regionales y organizaciones políticas locales de tentar a un puesto nacional. Cabe precisar que dentro de la esfera subnacional se encuentran puestos de gobierno municipal (distrital y provincial) y regional. En un estudio sobre el enraizamiento electoral en el ámbito subnacional durante el periodo 1963-2014, se daba cuenta de lo escasamente articulados que se encuentran los tres niveles de gobierno. Incio y Gil (2016) utilizan el Indicador de Enraizamiento Agregado (IEA) para comparar los resultados de las organizaciones políticas ganadoras en las elecciones subnacionales, así cons-

\footnotetext{
5 Los gobiernos regionales elegidos en 1989-1990 contaban con una asamblea regional (AR), un consejo regional (CR) y la Presidencia del Consejo, de acuerdo con el artículo 264 de la Constitución de 1979. Para este estudio, no hemos analizado los cargos de elección del periodo 1989-1990.
} 
truyeron el IEA provincial-distrital, regional-provincial y regional-distrital para encontrar coincidencias en los resultados.

Si bien las elecciones subnacionales cumplen un rol estratégico para los líderes políticos, ya que les sirve de escenario para preparar su maquinaria partidaria para las elecciones presidenciales, en la arena nacional, los liderazgos departamentales tienen dificultades para desarrollar una carrera política, por lo que resulta ser más apropiada para los dirigentes locales la participación electoral en sus departamentos ${ }^{6}$. En el Congreso, por ejemplo, los políticos locales enfrentan dificultades para abrirse camino a menos que pertenezcan a una clase política o tengan la confianza plena del partido por el que llegaron al cargo. Para Grompone, los políticos de la arena subnacional enfrentan factores adversos que impiden que puedan formar liderazgos regionales y que dificultan su paso a la esfera nacional (Grompone, 2012, pp. 35-36). El desprestigio de los partidos y del legislativo, los costos elevados para formar una organización nacional y la marginación de las élites locales, son algunos de los factores que desmotivan a los políticos de la arena subnacional a transitar posiciones ubicadas en la política nacional.

En ese sentido, para un político exitoso local que pretende ingresar a la arena nacional, las reglas que impone el sistema para la competencia pueden representar una barrera consideradamente alta, por lo que prefieran tal vez mantenerse en la esfera local y construir una carrera basada en reelecciones consecutivas a través de coaliciones coyunturales. Aunque, menos frecuente, estas condiciones pueden también impulsar a los políticos locales a invertir su capital en la construcción de una estructura partidaria que les permita competir en la arena nacional. El asociarse a partidos para poder postular a unos puestos nacionales sobrelleva costos de transacción altos para un político local que ha construido una reputación de independiente. En ese sentido, las coaliciones de independientes representan una forma más efectiva de competir electoralmente pero a nivel subnacional (Zavaleta, 2012, p. 15).

\footnotetext{
6 En una revisión rápida de la carrera política de los presidentes de la República, se observa que ninguno de los presidentes de la República del Perú ha ocupado el cargo de alcalde. Por ejemplo, a pesar que Lima concentra un tercio del electorado nacional, de los exalcaldes de Lima que postularon a la Presidencia de la República, ninguno logró el triunfo.
} 


\section{LA AMBICIÓN POLÍTICA EN EL NIVEL SUBNACIONAL PERUANO}

\subsection{Primeras aproximaciones}

En la política peruana la reelección se presenta como una condición necesaria entre las autoridades del nivel subnacional para no descender en su carrera política o para conservar las posibilidades de alcanzar más adelante cargos de elección superiores. No obstante, en la actualidad, no existen investigaciones en el Perú que hayan estudiado la ambición de los políticos locales y que identifiquen, por ejemplo, si el cargo de regidor o alcalde distrital es utilizado por la mayoría de los políticos como trampolín hacia puestos superiores o si, en efecto, existen casos de autoridades municipales con ambición progresiva que hayan logrado cargos electivos regionales o nacionales?.

En ese sentido, en cuanto a trabajos sobre ambición política en el Perú, se han logrado las primeras aproximaciones con Córdova e Incio (2013), quienes estudiaron a alcaldes y presidentes regionales que postularon a la reelección consecutiva en los años 2002, 2006 y 2010. Uno de sus principales hallazgos fue que la incumbencia no generaba una ventaja para los candidatos en el Perú, pues la mayoría de los candidatos incumbentes — distrital y provincial— no lograron ser reelectos. Es decir, la tasa de candidatos incumbentes no se reflejaba en la de incumbentes exitosos. En lo que refiere a los casos de «doble incumbencia», Córdova e Incio (2013) identificaron que los candidatos iban perdiendo varios puntos de una elección a otra. Entre los incumbentes de 2006 que ganaron las elecciones de 2010, encontraron que tuvieron una caída considerable de votos respecto a lo ganado en 2002 y 2006.

Más adelante, Aragón e Incio (2014) estudiaron la incumbencia en los procesos electorales de 2006, 2010 y 2014. Encontraron que más del 50\% de alcaldes distritales y provinciales buscaron ser reelectos para un periodo siguiente, presentándose el porcentaje más bajo de casos de incumbencia en la elección de 2014: el 60,62\% de los alcaldes distritales y el 52,31\% de los provinciales buscaron ser reelectos. Respecto a la tasa de reelección, el porcentaje de alcaldes reelectos no llega ni al 20\%, más aún se observa una disminución en el proceso de 2014: solo el 17\% de los alcaldes distritales y el 10\% de los alcaldes provinciales lograron permanecer en el cargo. Cabe precisar que la disminución que más llama la atención corresponde a los niveles de reelección de los presidentes regionales. Si bien el porcentaje de estas autoridades que

\footnotetext{
Hace más de una década se inició el proceso de descentralización en el Perú, que estableció tres niveles de gobierno: nacional, regional y municipal. Desde el proceso del año 2002, las elecciones regionales, provinciales y distritales se realizan simultáneamente cada cuatro años.
} 
postularon a la reelección se ha ido reduciendo en las dos últimas elecciones hasta llegar al 44\% en la elección de 2014, se observa que solo $16 \%$ de los presidentes regionales electos logró su segundo periodo consecutivo de mandato (2015-2020). Solo dos de cada cinco presidentes regionales que estaban terminando sus mandatos tentaron una reelección (Aragón e Incio, 2014).

\subsection{Generaciones de políticos locales 1980, 1993 y 2002}

Para el presente artículo se ha decidido formar tres grupos de políticos locales, conformados por regidores y alcaldes distritales, que corresponden a lo que llamamos tres «momentos» del sistema político peruano. La primera generación se inicia en la década de 1980, que se caracterizaba por el retorno a la democracia y la organización del sistema político alrededor de los partidos. La segunda generación se desarrolla en la década de 1990, iniciada con el gobierno de Alberto Fujimori y marcada por el golpe de Estado de 1992, donde el sistema político se centraba en el personalismo. Esta generación la conforman los alcaldes y regidores electos en el proceso municipal del ańo 1993. La tercera generación surge en la década de 2000, que inicia con el retorno a un sistema político más plural y democrático. Esta generación está conformada por las autoridades electas en las elecciones regionales y municipales que se organizaron por primera vez y de manera simultánea en el año 2002 como parte del proceso de la descentralización que se acaba de retomar.

Cabe señalar que las generaciones (cohortes) seleccionadas para esta investigación la integran solo alcaldes y regidores electos por primera vez en los procesos municipales de los años 1980, 1993 y 2002. Para cada caso, se analizará la trayectoria de las candidaturas que presentaron, tomando como punto de partida el ańo de los comicios donde fueron electos como alcalde o regidor, hasta la última elección, tanto municipal, regional como nacional, donde hayan participado. Es decir, analizaremos las trayectorias de los regidores y alcaldes distritales, desde el año en el que resultaron electos por primera vez para dichos cargos (1980, 1993 y 2002) hasta el último proceso electoral en que hayan participado. Por ejemplo, la generación de 1980 incluye solo a las autoridades distritales que lograron su primera elección como alcalde o regidor en los comicios municipales de 1980, pero se analiza su trayectoria a lo largo de todas las elecciones en las que haya alguna candidatura, tanto municipal, regional o nacional. Así también, la generación de 1993 incluye los regidores y alcaldes que fueron electos por primera vez en 1993, y la de 2002 a los electos por primera vez en aquella elección. 
Con el estudio de la ambición política en estas tres generaciones de autoridades distritales, buscamos encontrar diferencias entre ellas que de existir nos permitirían hipotetizar el posible efecto de estos tres momentos en las configuraciones de las trayectorias políticas o de la ambición de los políticos en el ámbito subnacional. La razón principal por la cual se analiza la ambición política de los alcaldes y regidores distritales es porque consideramos que en este nivel de gobierno se genera el espacio estratégico para los políticos con ambiciones a largo plazo, con posibilidades de lograr cargos de elección provinciales, regionales o nacionales ${ }^{8}$. Los datos que se han utilizado para construir las generaciones de políticos y los tipos de ambición consisten en resultados electorales oficiales obtenidos del Jurado Nacional de Elecciones a través de la plataforma virtual Infogob.

\subsection{Clasificación de las carreras políticas}

Hemos elaborado una clasificación de las carreras políticas, en función del tipo de ambición que manifiestan los políticos en una competencia electoral. Cabe recordar que las tres generaciones analizadas la integran políticos electos por primera vez como regidores y alcaldes distritales en los años 1980, 1993 y 2002. Para determinar el tipo de ambición se ha considerado el cargo más alto al que hayan postulado los regidores y alcaldes distritales en los procesos electorales posteriores a los años 1980, 1993 y 2002, según corresponda. El Cuadro 1 expone la relación de todas las elecciones estudiadas, donde los políticos locales pueden haber presentado candidaturas.

En el Cuadro 2 se muestran los cinco modelos de carreras junto con las trayectorias que emprenden los regidores y alcaldes distritales en cada una de ellas. Los dos primeros modelos corresponden a carreras ascendentes, donde prevalece la ambición progresiva que impulsa a los políticos a postular a un cargo de elección superior. En el Perú, existen tres niveles de gobierno de los cuales podrían participar para así construir una carrera progresiva, sea vertical u horizontal, e intentar alcanzar cargos de elecciones municipales — distrital y provincial—, regionales o nacionales.

En el caso de la carrera horizontal-progresiva, esta solo aplica para los regidores distritales que postulan al cargo de alcalde distrital. En una carrera vertical-progresiva, los regidores y alcaldes distritales postulan a cargos de elección

\footnotetext{
8 La ambición política puede dirigirle a ocupar la alcaldía distrital por un solo periodo o de mantenerse en ella por periodos consecutivos. También puede optar por ascender en su carrera política postulando a cargos de elección superiores al que ocupa, como la alcaldía provincial o la presidencia regional.
} 
del nivel provincial, regional o nacional. Mientras que en una carrera estática, postulan al mismo cargo que antes ocupaban, regidor y alcalde distrital, según sea el caso. Un caso atípico es la carrera regresiva, la cual se da en alcaldes distritales que postulan al puesto de regidor distrital. Por último, existen carreras muy cortas que manifiestan un tipo de ambición discreta, donde los regidores y alcaldes se retiran tempranamente de la arena política.

Cuadro 1. Procesos electorales analizados

\begin{tabular}{|c|c|}
\hline Grupos & Tipos de elección \\
\hline Generación de 1980 & $\begin{array}{l}\text { Elecciones generales } 1985-2011 \\
\text { Elecciones de parlamentarios andinos } 2006 \text { y } 2011 \\
\text { Elección de representantes de la Asamblea Regional } \\
\text { Elecciones regionales } 2002,2006,2010,2014 \\
\text { Elecciones de consejeros regionales } 2010 \text { y } 2014 \\
\text { Elecciones municipales distritales } 1983-2014 \\
\text { Elecciones municipales complementarias distritales 1981, 1985, 1987, 1991, } \\
1996,1999,2003 \text {, 2007, } 2011 \text { y } 2012 \\
\text { Elecciones municipales provinciales } 1983 \text {-2014 } \\
\text { Elecciones municipales complementarias provinciales 1981, 1985, 1987, } \\
1991,1996,1999 \text { y } 2004\end{array}$ \\
\hline Generación de 1993 & $\begin{array}{l}\text { Elecciones generales } 1995-2014 \\
\text { Elecciones de parlamentarios andinos } 2006 \text { y } 2011 \\
\text { Elecciones regionales 2002, 2006, 2010, } 2014 \\
\text { Elecciones de consejeros regionales } 2010 \text { y } 2014 \\
\text { Elecciones municipales distritales } 1995-2014 \\
\text { Elecciones municipales complementarias distritales 1996, 1999, 2003, } 2007 \text {, } \\
2011 \text { y } 2012 \\
\text { Elecciones municipales provinciales } 1995 \text {-2014 } \\
\text { Elecciones municipales complementarias provinciales 1996, } 1999 \text { y } 2004\end{array}$ \\
\hline Generación de 2002 & $\begin{array}{l}\text { Elecciones generales } 2006 \text { y } 2011 \\
\text { Elecciones de parlamentarios andinos } 2006 \text { y } 2011 \\
\text { Elecciones regionales 2006, 2010, } 2014 \\
\text { Elecciones de consejeros regionales } 2010 \text { y } 2014 \\
\text { Elecciones municipales distritales 2006-2014 } \\
\text { Elecciones municipales complementarias distritales 2003, 2007, } 2011 \text { y } 2012 \\
\text { Elecciones municipales provinciales 2006, 2010, } 2014 \\
\text { Elecciones municipales complementarias provinciales } 2004 \\
\text { Nuevas Elecciones Municipales } 2014\end{array}$ \\
\hline
\end{tabular}

Fuente: Infogob-JNE. Elaboración propia. 
Cuadro 2. Tipo de carrera política, según la ambición política

\begin{tabular}{|l|l|}
\hline \multicolumn{1}{|c|}{$\begin{array}{c}\text { Estructura de } \\
\text { carrera política }\end{array}$} & \multicolumn{1}{c|}{ Ejemplos de trayectorias* } \\
\hline $\begin{array}{l}\text { Carrera } \\
\text { horizontal-progresiva }\end{array}$ & Regidor distrital - alcalde distrital \\
\hline $\begin{array}{l}\text { Carrera } \\
\text { vertical-progresiva }\end{array}$ & $\begin{array}{l}\text { Alcalde distrital - alcalde provincial } \\
\text { Alcalde distrital - regidor provincial } \\
\text { Alcalde distrital - consejero regional } \\
\text { Alcalde distrital - presidente o vicepresidente regional ** } \\
\text { Alcalde distrital - congresista, asambleísta o parlamentario andino } \\
\text { Alcalde distrital - presidente o vicepresidente de la república } \\
\text { Regidor distrital - regidor provincial } \\
\text { Regidor distrital - alcalde provincial } \\
\text { Regidor distrital - consejero regional } \\
\text { Regidor distrital - presidente o vicepresidente regional } \\
\text { Regidor distrital - congresista, asambleísta o parlamentario andino } \\
\text { Regidor distrital - presidente o vicepresidente de la república }\end{array}$ \\
\hline Carrera estática & $\begin{array}{l}\text { Alcalde distrital - alcalde distrital } \\
\text { Regidor distrital - regidor distrital }\end{array}$ \\
\hline Carrera regresiva & Alcalde distrital - regidor distrital \\
\hline
\end{tabular}

Elaboración propia a partir de Lodola (2009), quien toma como referencia a otros autores que han estudiado la ambición política en el ámbito subnacional. *Como ejemplo, solo se muestran las trayectorias que emprenden los regidores y alcaldes distritales. ${ }^{* *}$ A través de la ley 30305 que modifica los artículos 191, 194 y 203 de la Constitución, la denominación del presidente y vicepresidente regional pasan a ser gobernador y vicegobernador regional respectivamente.

\section{ANÁLISIS DE LOS RESUltados}

\subsection{Carreras políticas de las generaciones 1980, 1993 y 2002}

Una mirada por generaciones nos permite explorar nuestra intuición sobre el efecto del contexto en el tipo de ambición y por ende en la clasificación de la carrera del político local. Solo en el Cuadro 3 ha sido necesaria la distinción entre regidores y alcaldes porque el mayor número de regidores en el total de la muestra terminaría por esconder las notables diferencias en cuanto a las carreras políticas que existen entre regidores y alcaldes distritales, lo cual logra detallarse al estudiarlas por separado. 
La ambición discreta ha predominado ampliamente entre los regidores de las tres generaciones, lo cual también da cuenta de la participación cada vez más extendida de políticos nuevos en estos cargos. Si bien el porcentaje más alto de ambición discreta se observa en los regidores de la generación de 1993, este patrón no se repite en el caso de los alcaldes distritales. Al parecer, el desplome de los partidos y el auge de los independientes de la década de 1990 afectaron más a los regidores. Por el contrario, casi la totalidad de los alcaldes de dicha generación optaron por la reelección, mientras que las carreras discretas destacaron solo en la generación de 1980 con 66,46\% y cobraron fuerza en la de 2002 con 15,03\%.

En el caso de los alcaldes, la carrera estática ha sido la más recurrente no solo en la generación de 1993, sino también en la de 2002, aunque con porcentaje menor. Contrario a lo que se esperaría, la ambición estática alcanzó su punto más bajo en la generación de 1980, con solo el 20,41\% de alcaldes postulando a la reelección. A pesar de que, a inicios de la década de 1980, los partidos contaban con mayor presencia a nivel subnacional, al parecer, esto no fue un buen incentivo para la generación de alcaldes, quienes en su mayoría optaron por el retiro, mientras solo un número reducido decidió continuar con una carrera.

Por otra parte, la carrera horizontal progresiva da cuenta del interés que tienen los políticos por acceder a posiciones ubicadas en un mismo nivel de gobierno. Esta carrera es solo aplicable para los regidores que integran nuestra muestra, para quienes su ambición los orienta hacia la alcaldía distrital. En el Cuadro 3, se observa que, entre los regidores, el interés por la alcaldía distrital ha sido mayor en la generación de 2002, con un 10,14\%, mientras que en la generación de 1993, apenas el 2,37\% ambicionó dicho cargo ejecutivo.

Respecto a la carrera vertical-progresiva, esta ha tenido una presencia mínima en los regidores para quienes el ascenso hacia cargos ubicados en diferentes niveles de gobierno no ha sido lo suficientemente atractivo. En las generaciones de 1980 y 1993, la carrera vertical-progresiva ha tenido una presencia de $2,47 \%$ y $2,11 \%$, respectivamente, con un incremento en la generación de 2002, donde el 5,41\% de los políticos locales desarrollaron dicha carrera. Una tendencia parecida se observa en el caso de los alcaldes, donde este tipo de carrera aumentó notablemente en la generación de 2002, con un porcentaje superior a lo alcanzado por aquellos alcaldes con ambición discreta.

El análisis de la carrera regresiva solo ha sido aplicable a los alcaldes distritales. Según el Cuadro 3, el porcentaje de alcaldes que emprendieron trayectorias descendentes, al postular al cargo de regidor distrital, ha sido minúsculo en las dos últimas generaciones estudiadas. No obstante, algo singular ocurrió en la generación de 1980, donde un 6,65\% desarrollaron carreras descendentes en los procesos electorales siguientes. 
Cuadro 3. Tipo de carrera política en las generaciones 1980, 1993 y 2002

\begin{tabular}{|l|l|l|l|l|l|l|}
\hline \multirow{2}{*}{ Tipo de carrera política } & \multicolumn{3}{c|}{ Alcaldes } & \multicolumn{3}{c|}{ Regidores } \\
\cline { 2 - 7 } & 1980 & 1993 & 2002 & 1980 & 1993 & 2002 \\
\hline Carrera horizontal-progresiva & & & & $3,99 \%$ & $2,37 \%$ & $10,14 \%$ \\
\hline Carrera vertical-progresiva & $6,48 \%$ & $3,40 \%$ & $18,51 \%$ & $2,47 \%$ & $2,11 \%$ & $5,41 \%$ \\
\hline Carrera regresiva & $6,65 \%$ & $0,12 \%$ & $0,32 \%$ & & & \\
\hline Carrera estática & $20,41 \%$ & $96,13 \%$ & $66,14 \%$ & $21,18 \%$ & $6,80 \%$ & $20,26 \%$ \\
\hline Carrera discreta & $66,46 \%$ & $0,35 \%$ & $15,03 \%$ & $72,38 \%$ & $88,72 \%$ & $64,19 \%$ \\
\hline
\end{tabular}

Total de muestra: Generación $1980=1127$ alcaldes y 7738 regidores. Generación $1993=852$ alcaldes y 6073 regidores. Generación 2002 = 632 alcaldes y 6250 regidores. Fuente: Infogob-JNE. Elaboración propia.

\subsection{Orientación de la ambición política de las generaciones 1980, 1993 y 2002}

En el Cuadro 4 se observa como la orientación de la ambición política en las tres generaciones se ha concentrado abrumadoramente en el mismo nivel de gobierno que ocupaban previamente9. En más del $90 \%$ de los políticos locales de las generaciones de 1980 y 1993 y el 85\% de la generación de 2002, orientaron su futuro hacia posiciones ubicadas en el nivel distrital. Por otra parte, la presencia de políticos distritales que alternaron posiciones en los niveles de gobierno provincial y regional ha sido mínima; sin embargo, en la generación de 2002, los cargos de elección provincial se incrementó en 10,41\%, mientras que las preferencias por puestos en el nivel regional ha ido en ascenso.

Si bien la ambición por cargos de elección en los niveles regional y nacional ha sido muy reducida, se observa una mayor movilidad hacia cargos nacionales entre los políticos distritales de las generaciones de 1980 y 1993. Esta situación se invierte en la generación de 2002, donde el 2,81\% de políticos trasladaron su interés hacia puestos regionales, frente al $0,86 \%$ de regidores y alcaldes que postularon a cargos nacionales. La creación de los gobiernos regionales y la convocatoria a elecciones regionales y municipales para el año 2002 coincide con este mayor interés por puestos en la arena subnacional.

\footnotetext{
9 En afán de ganar claridad, así como evitar una discusión repetitiva y confusa, en el Cuadro 4 se ha analizado de manera conjunta la orientación de la ambición de los políticos locales, tanto de alcaldes como regidores.
} 
Cuadro 4. Orientación de la ambición política de las generaciones de 1980, 1993 y 2002

\begin{tabular}{|l|l|c|c|c|}
\hline \multicolumn{2}{|c|}{ ¿A dónde se orienta la ambición política? } & $\begin{array}{c}\text { Generación } \\
1980\end{array}$ & $\begin{array}{c}\text { Generación } \\
1993\end{array}$ & $\begin{array}{c}\text { Generación } \\
2002\end{array}$ \\
\hline \multirow{2}{*}{ Arenal subnacional } & Nivel distrital & $91,18 \%$ & $91,07 \%$ & $85,91 \%$ \\
\cline { 2 - 5 } & Nivel provincial & $6,19 \%$ & $4,76 \%$ & $10,41 \%$ \\
\cline { 2 - 5 } & Nivel regional & $0,75 \%$ & $1,24 \%$ & $2,81 \%$ \\
\hline Arena nacional & Nivel nacional & $1,88 \%$ & $2,93 \%$ & $0,86 \%$ \\
\hline
\end{tabular}

Total de muestra: $1980=2812 ; 1993=1534 ; 2002=2775$.

Fuente: Infogob-JNE. Elaboración propia.

\section{Conclusiones}

Existen importantes elementos caracterizadores de la arena subnacional en el Perú, en cuanto a la ambición y carreras políticas, para diferenciarla de la arena nacional. Además de que los puestos de representación en la arena nacional son menos, los casos de políticos locales que orientan su ambición hacia cargos de elección nacionales no ha sido recurrente en la arena subnacional, entre otros factores, porque las barreras para el ingreso a la clase política nacional son muy altas, tanto el desprestigio de los partidos nacionales y del legislativo, así como los costos elevados para formar una organización nacional desmotivan a los políticos locales de orientar su futuro hacia puestos nacionales. Por el contrario, el estudio de la ambición política en las generaciones de 1980, 1993 y 2002 da cuenta del interés mayor de los políticos locales por permanecer en puestos del nivel distrital, unos a través de la reelección y otros, en el caso de los regidores, postulando a la alcaldía distrital. Esta poca permeabilidad que existe entre lo subnacional y lo nacional, genera una desconexión que no ayuda a la institucionalización del sistema de partidos, al reducir las posibilidades de renovación en las élites nacionales y la profesionalización política.

En la década de 1980 los partidos gozaban de un auge y de una fortaleza institucional, por lo que se esperaría que en la generación de políticos locales de 1980 hubiera más políticos ambiciosos; sin embargo, se observa una presencia mayoritaria de carreras discretas, tanto en alcaldes como regidores. En el caso de los políticos locales de la generación de 1980 que optaron por continuar una carrera, la ambición estática ha predominado por sobre otras. El 20\% de regidores y alcaldes de dicha generación encontraron mayores incentivos para postular a la reelección que alternar hacia otras posiciones de gobierno. 
En la generación de 1993, en cambio, la ambición discreta debió ser mayor al de las otras dos generaciones, al encontrarse el sistema de partidos colapsado. En efecto, la generación de 1993 tiene el porcentaje más alto de regidores con carreras discretas (88,72\%); no obstante, en los alcaldes la situación es distinta al encontrarse que casi la totalidad de la generación postuló a la reelección, habiéndose retirado tempranamente de la vida política electoral solo un $0,35 \%$ de los alcaldes.

En la generación de 2002, los alcaldes se han caracterizado por emprender carreras estáticas, mientras que más de la mitad de los regidores no han vuelto a postular a ningún cargo de elección. Si bien existe una mayor presencia de alcaldes ambiciosos, en ambos políticos se ha encontrado un relativo incremento en la alternancia hacia puestos de diferentes niveles de gobierno. Aunque son pocas las elecciones analizadas para la generación de 2002, esta situación descrita evidencia la posible reorganización de una carrera progresiva pero asentada en lo subnacional. La transición de lo distrital a lo provincial se ha incrementado en la generación de 2002, mientras que el paso hacia cargos regionales comienza a despertar el interés de los políticos distritales. Sin embargo, es necesario observar con mayor detenimiento a esta joven generación y considerar los posibles impactos de la no reelección para llegar a datos más concluyentes.

El impacto de la eliminación de la reelección podría generar mayor ambición discreta en la arena subnacional y con ello menores opciones para la formación de políticos de carrera. De acuerdo con nuestro estudio, la carrera estática ha sido la más recurrente en las tres generaciones, incluso se observa un aumento en la generación de 2002, donde los regidores y alcaldes distritales postularon a la reelección.

Finalmente, con este trabajo esperamos incentivar la investigación sobre el nivel subnacional y, sobre todo, responder otras preguntas que nos lleven a conocer mejor al político local. 


\section{Bibliografía}

Abramowitz, A. (1991). Incumbency, Campaign Spending and the Decline of Competition in U.S House of Representatives. The Journal of Politics, 53(1), 34-56.

Aldrich, J. H. (2012). ¿Por qué los partidos políticos?: Una segunda mirada. Madrid, España: Centro de Investigaciones Sociológicas.

Aldrich, J. H. y Bianco, W. T. (1992). A game-theoretic model of party affiliation of candidates and office holders. Mathematical and Computer Modeling, 16(8/9), 103-116.

Almaraz, M. G. (2010). Ambición política por la reelección en las provincias argentinas. Revista SAAP, 4(2), 192-226.

Aragón, J. e Incio, J. L. (2014). La reelección de autoridades regionales y municipales en el Perú, 2006-2014. Revista Argumentos, 8(5), 16-30. Recuperado de http://revistaargumentos.iep.org. pe/articulos/la-reeleccion-de-autoridades-regionales-y-municipales-en-el-peru-2006-2014/

Black, G. S. (1972). A Theory of Political Ambition: Career Choices and the Role of Structural Incentives. American Political Science Review, 66(1), 144-159. doi: 10.2307/1959283

Botero, F. (2011). Carreras políticas en América Latina (2011). Discusión teórica y ajuste de supuestos. PostData, 16(2), 167-187. Recuperado de http://www.scielo.org.ar/scielo. php?script=sci_arttext\&pid=S1851-96012011000200002

Campomar, B. y Delneri, M. P. (noviembre de 2012). Carrera política de los gobernadores en Argentina. Trabajo presentado en el Cuarto Congreso Uruguayo de Ciencia Política: La Ciencia Politica desde el Sur. Montevideo, Uruguay.

Córdova, B. y Incio, J. L. (2013). La ventaja del incumbente en el ámbito subnacional: un análisis de las dos últimas elecciones municipales. Papel Político, 18(2), 415-436. Recuperado de http:// www.redalyc.org/articulo.oa?id $=77729796002$

Díaz Rebolledo, J. (2005). Los determinantes de la indisciplina partidaria. Apuntes sobre la conexión electoral en el Congreso mexicano, 2000-2003. Política y Gobierno. México, 12(2), 313330. Recuperado de http://www.redalyc.org/pdf/603/60327291004.pdf

Erikson, R. S. (1971). The Advantage of Incumbency in Congressional Elections. Polity, 3(3), 395405. doi : $10.2307 / 3234117$

Ferejohn, J. (1977). On the Decline of Competition in Congressional Elections. The American Political Science Review, 71(1), 166-176. doi: 10.1017/S0003055400259364

Gardner, J. (1991). The Uses and Abuses of Incumbency: People v. Ohrenstein and the Limits of Inherent Legislative Power. Fordham Law Review, 60(2), 217-255. Recuperado de http:// ir.lawnet.fordham.edu/Ar/vol60/iss $2 / 1 /$.

Grompone Grille, R. (2012). La creciente vigencia de movimientos y partidos regionales: sus alcances y limites. Lima, Perú: IEP.

Incio, J. L. y Gil, R. (2016). Enraizamiento electoral en ámbitos subnacionales. Análisis de las organizaciones político-electorales peruanas (1963-2014). Revista Uruguaya de Ciencia Politica, 25(1), 115-136. Recuperado de http://www.redalyc.org/pdf/2973/297346770003.pdf

Jones, M. P. (1997). Evaluating Argentina’s presidential democracies 1983-1995. En S. Mainwaring y M. Shugart (eds.), Presidentialism and democracy in Latin America (pp. 259-299). Cambridge, Reino Unido: Cambridge University Press. doi: 10.1017/cbo9781139174800.008

Jones, M. P. (2001). Carreras políticas y disciplina partidaria en la cámara de diputados Argentina. PostData, (7), 189-230. Recuperado de http://www.revistapostdata.com.ar/2011/12/ carreras-politicas-y-disciplinas-partidarias-en-la-camara-de-diputados-argentina-mark-p-jones/

Jones, M. P. (2008). The recruitment selection of legislative candidates in Argentina. En P. M. Siavelis, y S. Morgenstern (eds.), Pathways to power: political recruitment and democracy in Latin America (pp. 41-75). Pennsylvania, PA: Pennsylvania State University Press. 
Jones, M. P., Saiegh, S., Spiller, P. T. y Tommasi, M. (setiembre de 2002). Políticos profesionales- Legisladores «amateurs»: El Congreso argentino en el siglo XX. Artículo presentado en Conferencia Anual de la Sociedad Internacional de la Nueva Economía Institucional, Tübingen, Alemania.

Lodola, G. (2009). La estructura subnacional de las carreras políticas en Argentina y Brasil. Desarrollo Económico, 49(194), 247-286.

Lodola, G. y Almaraz, M. G. (julio de 2013). Reclutamiento político, patrones de carrera y ambiciones de gobernadores en Argentina y Brasil. Artículo presentado en el Congreso de Ciencia Política de Paraná. Paraná, Argentina.

Martínez, M.M. (2010). Ambición política y lealtad. Influencia sobre el comportamiento político. Politica y gobierno, 18(2), 231-264.

Mayhew, D. (1974). Congress: The electoral connection. New Haven, CT: Yale University Press.

Micozzi, J. P. (2009). The electoral connection in multi-level systems with non-statistic ambition: linking political careers and legislative performance in Argentina. Tesis doctoral para acceder al título de Doctor en Filosofía, Rise University, Houston, United States.

Miller, W. y Stokes, D. (1963). Constituency Influence in Congress. The American Political Science Review, 57(1), 45-56. doi: 10.2307/1952717

Morgenstern, S. (2004). Patterns of Legislative Politics. Roll-Call Voting in Latin America and the United States. Nueva York, NY: Cambridge University Press.

Rohde, D. W. (1979). Risk-Bearing and Progressive Ambition: The Case of the Members of the United States House of Representatives. American Journal of Political Science, 23, $126-$ 150. doi: $10.2307 / 2110769$

Samuels, D. (2011). Ambición política, reclutamiento de candidatos y política legislativa en Brasil. POSTData, 16(2), 281-307. Recuperado de http://www.scielo.org.ar/scielo. php?pid=S1851-96012011000200006\&script=sci_arttext

Schaffner, B., Streb, M. y Wright, G. (2001). Teams Without Uniforms: The Nonpartisan Ballot in State and Local Elections. Political Research Quarterly, 54(1), 7-30. doi: 10.2307/449205

Schlesinger, J. A. (1966). Ambition and Politics: Political Careers in the United States. S/1: Rand McNally.

Seifert Bonifaz, M. (2014). Colapso de los partidos nacionales y auge de los partidos regionales. Las elecciones regionales y municipales 2002-2010. Lima, Perú: PUCP-Escuela de Gobierno y Políticas Públicas.

Tanaka, M. (2005). Democracia sin partidos: Perú, 2000-2005: los problemas de representación y las propuestas de reforma politica. Lima, Perú: IEP.

Tchintian, C. (2009). Gobernadores en política nacional. Una revisión teórica. Colección, 15(20), 107-132.

Tuesta Soldevilla, F. (11 de setiembre de 2014). Partido entre Lima y el país. La República, p. 4.

Zavaleta, M. (2012). La competencia politica post-Fujimori. Partidos regionales y coaliciones de independientes en los espacios subnacionales peruanos. Tesis para optar el Título de Licenciado en Ciencia Política y Gobierno, PUCP, Lima, Perú. 